\title{
PREDICTION OF THE OVERLOADED AXIAL TURBINE STAGE EFFICIENCY USING THE HYBRID RANS/LES TURBULENCE MODEL
}

\author{
Straka P.*, Pelant J.**
}

\begin{abstract}
The paper deals with application of hybrid RANS/LES turbulence model for computation of flow in axial turbine stage at off-design operation regime. This operating regime is characterized by massive separation of the boundary layer on the suction side of the rotor blades which leads to high-swirl flow field behind the axial stage. Used hybrid RANS/LES model is based on transport equation for the kinetic energy which is shared in both RANS and LES modes. The model is implemented into the in-house numerical code which was originally designed for solution of RANS equation. Therefore the numerical inviscid fluxes are modified here in order to reduce a native numerical dissipation for use in LES approach
\end{abstract}

Keywords: Hybrid RANS/LES, Axial turbine stage, Secondary flows.

\section{Introduction}

The contribution deals with numerical simulation of flow in the axial turbine stage under the off-design conditions. Fig. 1 shows dependency of the normalized total-total and total-static efficiency on the rotational speed. The rotational speed is described by the similarity parameter $u / c$, where $u$ is the speed of rotation and $c$ is the outlet isentropic velocity. Note that the total-total efficiency and total-static efficiency are given as $\eta_{T T}=\left(T_{T 0}-T_{T}\right) /\left(T_{T 0}-T_{T i s}\right), \eta_{T S}=\left(T_{T 0}-T_{T}\right) /\left(T_{T 0}-T_{S i s}\right)$, where $T_{T 0}$ is the inlet total temperature, $T_{T}$ is locale value of the total temperature, $T_{T i s}$ is the isentropic total temperature and $T_{S i s}$ is the isentropic static temperature. From Fig. 1 one can found optimal rotational speed of around $u / c=0.65$. Decreasing of the efficiency for higher $(u / c>0.8)$ and lower $(u / c<0.45)$ rotational speed is given by separation of the boundary layer on the pressure and suction side of the rotor blades respectively.

Whereas the separation on the pressure side of the rotor blade affects the tip region only, the separation on the suction side occurs on entire span of the rotor blade.

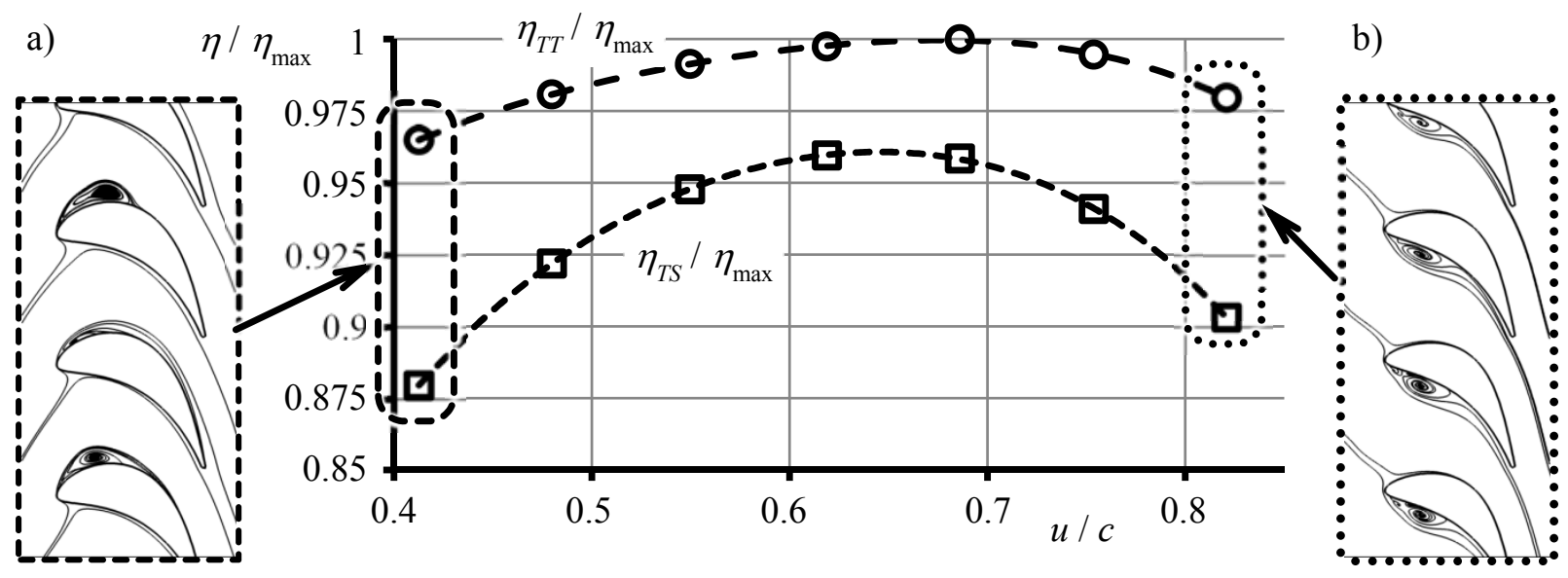

Fig. 1: Dependency of the stage efficiency on the rotational speed; a) separation on the suction side of the rotor blades for lower rotational speed; b) separation on the pressure side of the rotor blades for higher rotational speed.

\footnotetext{
* Ing. Petr Straka, PhD.: Czech aerospace research centre; Beranových 130, 19905 Prague; CZ, straka@vzlu.cz

** RNDr. Jaroslav Pelant, CSc.: Czech aerospace research centre; Beranových 130, 19905 Prague; CZ, pelant@vzlu.cz
} 


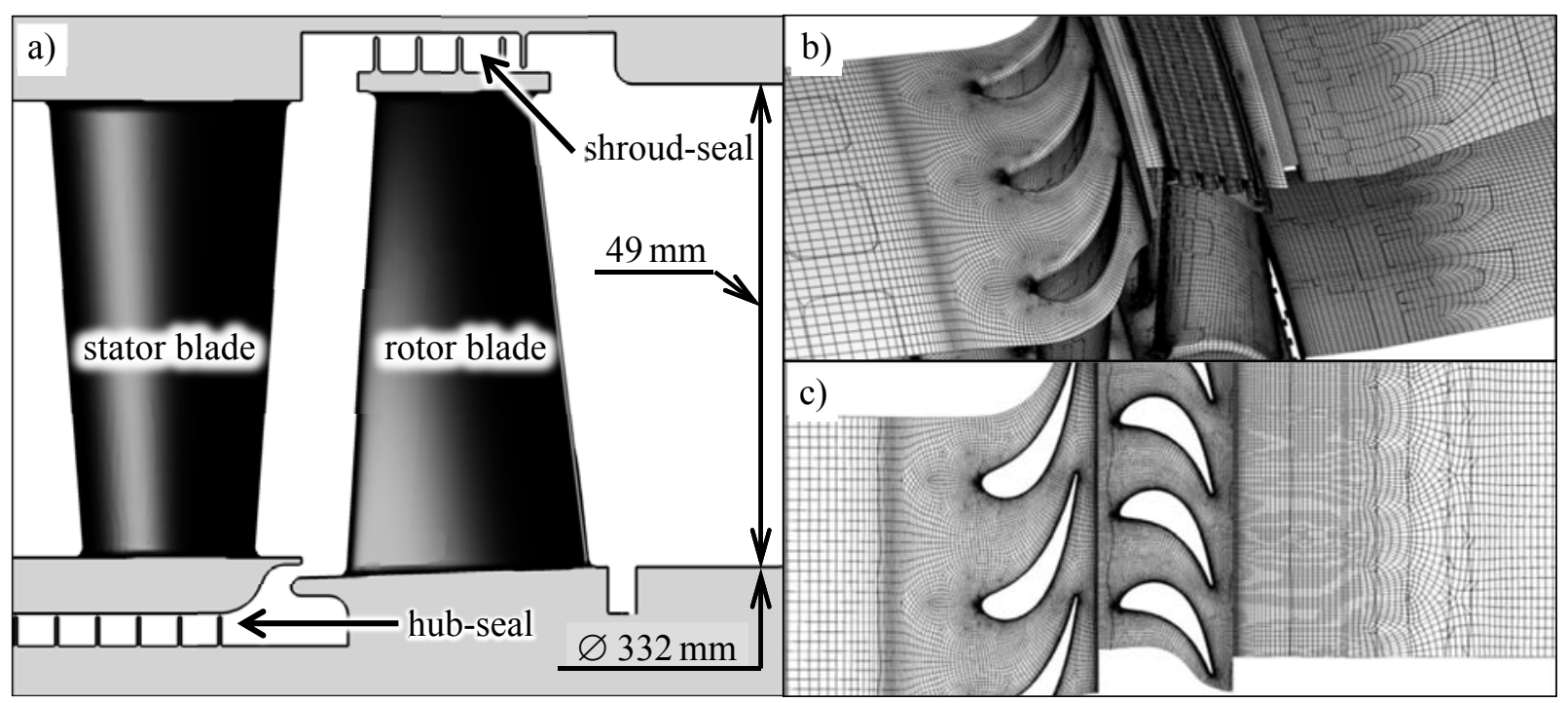

Fig. 2: a) Scheme of the axial turbine stage equipped with the shroud-and hub-seals; b), c) the computational mesh.

Present contribution deals with simulation of regime $u / c=0.41$ with separation on the suction side using the hybrid RANS/LES approach. Calculation was performed using the in-house code based on solution of system of averaged/filtered Navier-Stokes (NS) equations by the finite volumes discretization method. More details can be found in (Straka, 2015, 2016a, 2106b). The system of governing equation is closed with two-equation turbulence model based on nonlinear explicit algebraic relation for the Reynolds stress tensor proposed by Rumsey and Gatski (2001). Fig. 2a shows scheme of the axial turbine stage equipped with the hub- and shroud-seal. Used computational mesh is shown in Figs. $2 \mathrm{~b}$ and 2c.

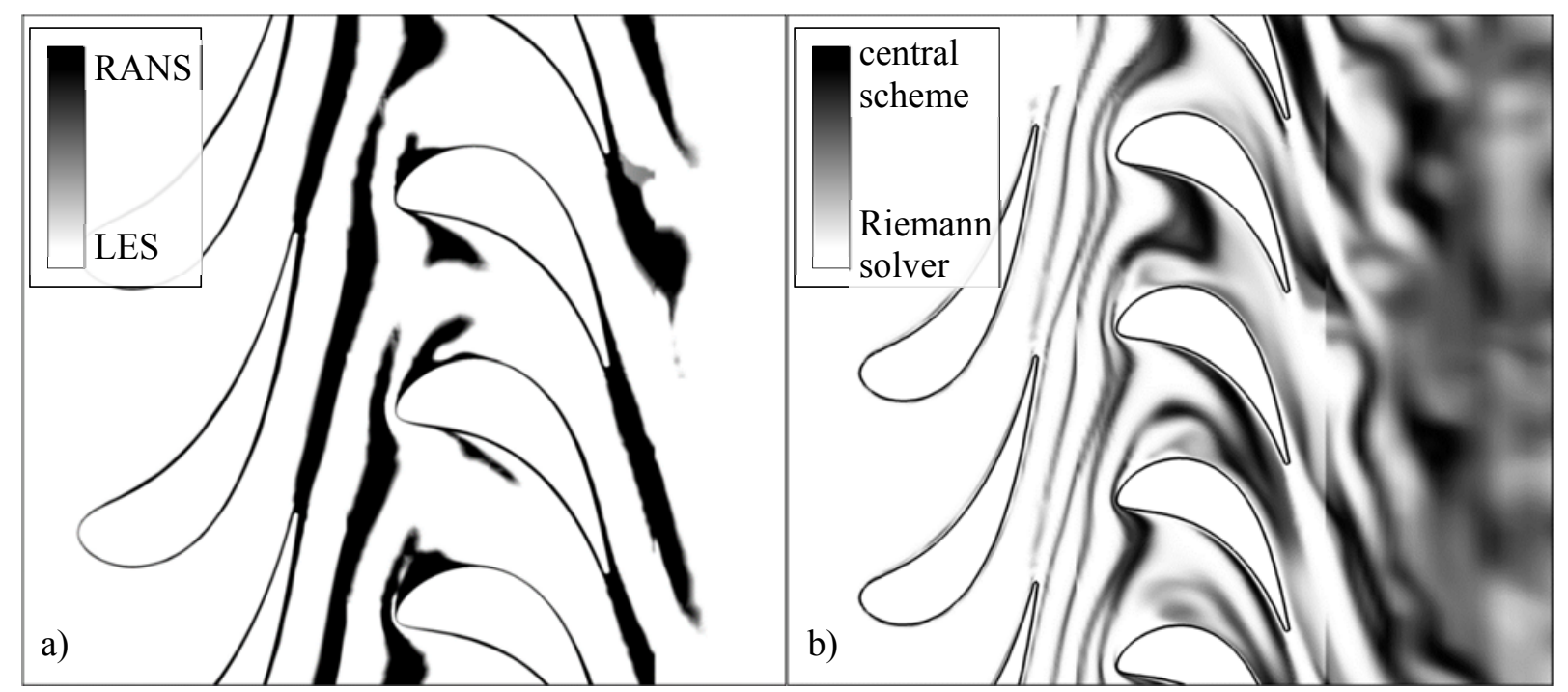

Fig. 3: a) domains of the RANS and LES models; b) domains of application the central scheme and the Riemann solver.

\section{Physical model, numerical methods}

The hybrid RANS/LES turbulence model proposed by (Davidson and Peng, 2003; Kok et al., 2004) is based on solution of averaged NS equations in regions near the walls and on solution of filtered NS equations in region of large detached eddies. Both parts (RANS and LES) of the model shares the same transport equation for the turbulent energy $k$. In RANS regime this equation is complemented by second transport equation for specific dissipation rate $\omega$.

$$
\frac{D(\rho k)}{D t}=P_{k}-\max \left(\beta^{*} \rho k \omega, \frac{\rho \sqrt{k^{3}}}{C_{D E S} \Delta}\right)+\frac{\partial}{\partial x_{j}}\left[\left(\mu+\sigma_{k} \frac{\rho k}{\omega}\right) \frac{\partial k}{\partial x_{j}}\right],
$$




$$
\frac{D(\rho \omega)}{D t}=\alpha \frac{\omega}{k} P_{k}-\beta \rho \omega^{2}+\frac{\partial}{\partial x_{j}}\left[\left(\mu+\sigma_{\omega} \frac{\rho k}{\omega}\right) \frac{\partial \omega}{\partial x_{j}}\right]+C_{D},
$$

where $\rho$ is the density, $P_{k}$ is the production term, $C_{D}$ is the cross diffusion term, $\alpha, \beta^{*}, \beta, \sigma_{k}$ and $\sigma_{\omega}$ are model constants. The local grid size $\Delta$ is defined by $\Delta=\max \left(\Delta_{\xi}, \Delta_{\eta}, \Delta_{\xi}\right)$ where $\Delta_{\xi}, \Delta_{\eta}$ and $\Delta_{\zeta}$ are the distances between the cell faces in local $\xi, \eta$ and $\zeta$ grid line directions. Constant $C_{D E S}=0.6086$ is chosen according to (Kubacki et al., 2013). The turbulent/sub-grid-scale viscosity is given as $\mu_{t}=\min \left(\rho k / \omega, \rho \beta^{*} C_{D E S} \sqrt{k} \Delta\right)$. Note that in LES regime the model does not depend on transport equation for the dissipation rate $\omega$.

The vector of inviscid numerical fluxes $\mathbf{F}$ is calculated using the exact solution of the 1D Rieman problem in normal direction to the cell edges (referred as $\mathbf{F}_{R S}$ ). Although this approach has good features for the RANS modelling, it is too dissipative for the LES. Therefore for suppression of native numerical dissipation the central differencing scheme is used in LES domain (referred as $\mathbf{F}_{C}$ ). The resulting inviscid numerical flux vector can be formally written as $\mathbf{F}^{\text {modif }}=\psi \mathbf{F}_{C}+(1-\psi) \mathbf{F}_{R S}$, where $\psi=[0.5-0.5 \cos (2 \pi \lambda)]^{2}$. The parameter $\lambda$ is limited ratio of the sub-grid and the turbulent length scales $\lambda=\max \left[0,1-\left(C_{D E S} \Delta\right) /\right.$ $\left(k^{0.5} / \beta^{*} \omega\right)$ ]. In Fig. 3a there are displayed domains of RANS and LES parts of hybrid turbulence model. Note that in the LES domain it holds $\left(C_{D E S} \Delta\right)<\left(k^{0.5} / \beta^{*} \omega\right)$. Fig. $3 b$ shows the area of application the central differencing scheme.

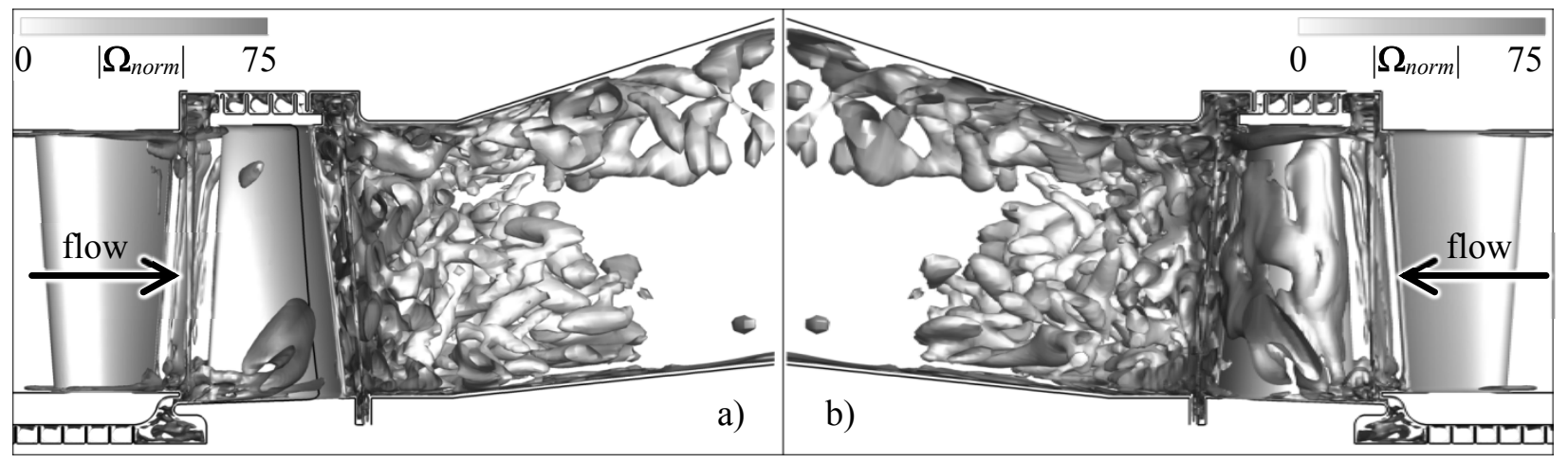

Fig. 4: Structure of vortices behind the axial turbine stage - isosurfaces of $Q=\left(\Omega^{2}-\mathbf{S}^{2}\right)$ coloured with the normalized vorticity magnitude $\left|\Omega_{\text {norm }}\right|$; view on the pressure side (a) and on the suction side (b) of the rotor blade.

\section{Results}

Fig. 4 shows high-swirl flow field behind the axial stage in form of isosurfaces of $Q=\left(\Omega^{2}-\mathbf{S}^{2}\right)$, where $\Omega^{2}=2 \Omega_{i j} \Omega_{i j}, \mathbf{S}^{2}=2 S_{i j} S_{i j}, \Omega_{i j}$ is the vorticity tensor and $S_{i j}$ is the strain rate tensor. Instantaneous and time averaged distributions of the total-static efficiency $\eta_{T S}$ in section $10 \mathrm{~mm}$ behind the rotor blades are shown in Fig. 5 (for clarity in the cylindrical coordinate system). In Fig. 6 there are compared span-wise
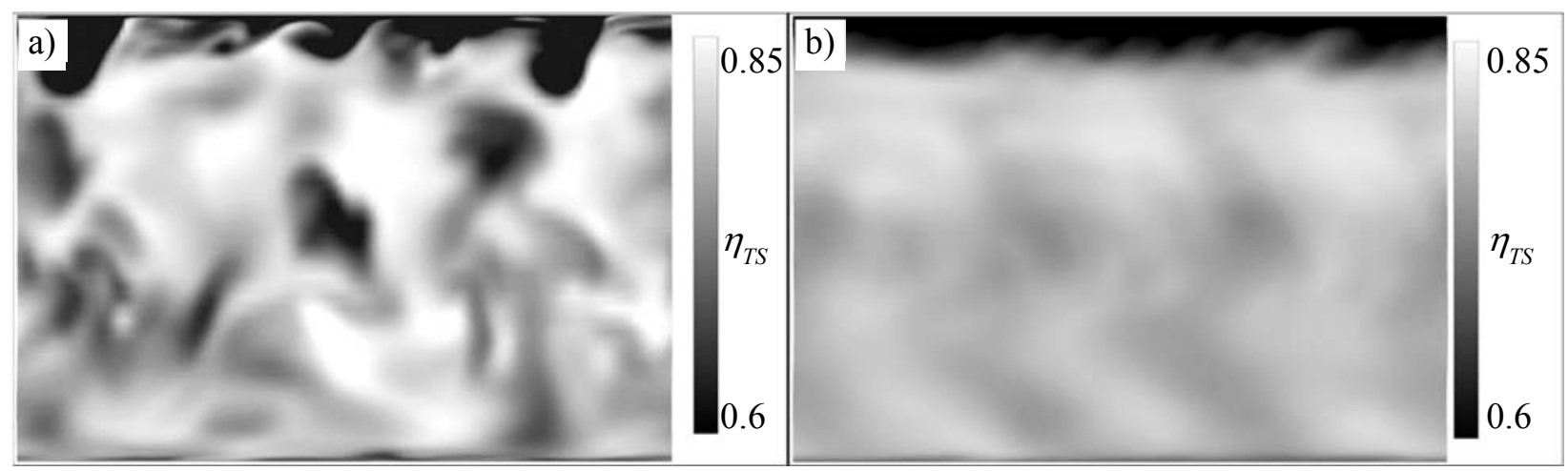

Fig. 5: Distribution of the total-static efficiency $\eta_{T S}$ in plane $10 \mathrm{~mm}$ behind the rotor blades; a) instantaneous field; b) time averaged field; (shown in the cylindrical coordinates). 


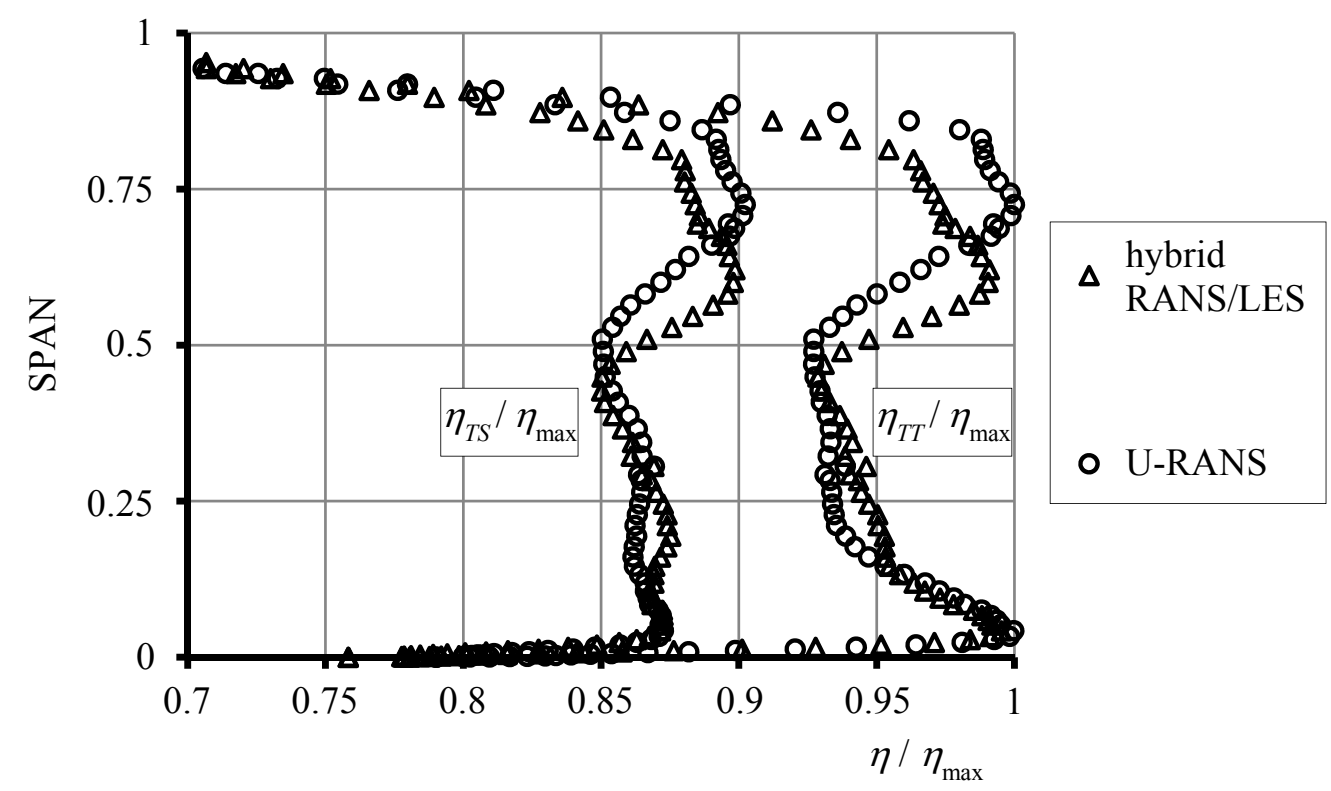

Fig. 6: Span-wise distribution of normalized total-total and total-static efficiency-comparison of the hybrid RANS/LES and the unsteady RANS approaches.

distributions of normalized total-total and total-static efficiency of the hybrid RANS/LES and the unsteady RANS approaches. One can find differences in upper half of the span, namely in area of influence of leakage flows from the shroud-seal at approx. 75 percent of the span.

\section{Conclusions}

Hybrid RANS/LES model was implemented into the in-house numerical code which was here modified for using in LES approach. Benefit of the hybrid RANS/LES approach is that it allows to simulate behavior of large detached eddies in high-swirl flow field, but contrary to the full resolved LES it does not increase the computational costs. The needed computational time is comparable to the unsteady RANS approach.

\section{Acknowledgement}

The work was realized within the project No. TN01000007 National Centre for Energy. The project is cofinancing by the government support of Technology Agency of the Czech Republic within the program of National Centers of Competency.

\section{References}

Davidson, L., Peng, S. H. (2003) Hybrid LES-RANS modelling: a one-equation SGS model combined with a $k-\omega$ model for predicting recirculating flows. Int. Jour. Numer. Meth. Fluids, 43, pp. 1003-1018.

Kok, J. C., Dol, H. S., Oskam, B. \& H. van der Ven (2004) Extra-large eddy simulation of massively separated flows. AIAA paper, 2004-264.

Kubacki, S., Rokicki, J., Dick, E., Degroote, J., Vierendeels, J. (2013) Hybrid RANS/LES of plane jets impinging on a flat plate at small nozzle-plate distances. Arch. Mech., 65, 2, pp. 143-166.

Rumsey, C. L., Gatski, T. B. (2001) Recent turbulence model advances applied to multielement airfoil computations. Jour. of Aircraft, 38, 5, pp. 904-910.

Straka, P. (2015) Numerical simulation of high-swirl flow in axial turbine stage. Proc. Conf. Experimental Fluid Mechanics 2015 (Dančová, P. \& Veselý, M. eds), Prague, pp. 752-759.

Straka, P. (2016a) Modelling of unsteady secondary vortices generated behind the radial gap of the axial turbine blade wheel. Proc. Conf. ECCOMAS Congress 2016, Crete.

Straka, P. (2016b) Hybrid RANS/LES modelling of secondary flow in axial turbine stage. Proc. Conf. Engineering Mechanics 2016. Svratka. 